\title{
Statistical prediction of maximum avalanche run-out distances from topographic data in the western Catalan Pyrenees (northeast Spain)
}

\author{
Glòria Furdada, Joan Manuel Vilaplana \\ Departament de Geodinàmica i Geofísica, Universitat de Barcelona, 08028 Barcelona, Spain
}

\begin{abstract}
We present regression models to estimate maximum avalanche run-out distances in the western Catalan Pyrenees (northeast Spain). The regression equations have been calculated from topographic parameters of 216 well-known avalanche paths, mapped on avalanche location maps at a scale of 1:50 000. Historical information about avalanche maximum run-out zones has been available for some avalanche paths but most of them have been delimited by vegetation and geomorphological indices.

The avalanche profiles, which are representative of avalanche paths, have been classified on the basis of avalanche run-out zone morphology, because this has a considerable influence on avalanche behaviour and run-out. Three classes have been defined and regression equations obtained for each class and also for the total. Finally, some examples have been calculated in order to appreciate the applicability of the models to improving avalanche mapping.
\end{abstract}

\section{INTRODUCTION}

Altitudes in the study area in the Catalan Pyrenees range from 500 to $3000 \mathrm{~m}$, with vertical drops of around $1500 \mathrm{~m}$ from crests to bottoms of the main valleys. The bottoms of the main valleys are usually narrower than $750 \mathrm{~m}$. This region is characterized by glacial forms (from the last Quaternary glaciation), with a majority of $\mathrm{U}$-shaped valleys and with cirques and topographic thresholds at the highest altitudes. Avalanches develop on these slopes. A number of villages, tourist complexes and related facilities are being built in the studied area; hence, the need for accurate avalanche maps. Initially, these maps can be used as a tool for land-use planning to avoid, wherever possible, threatened areas.

Avalanche-location maps at a scale of 1:50000 have been compiled by the Servei Geològic (Institut Cartogràfic de Catalunya, Generalitat de Catalunya) in collaboration with the Departament de Geologia Dinàmica, Geofisica i Paleontologia (Universitat de Barcelona) since 1988. Sometimes, because of a lack of historical information or because the morphologic and vegetation indices are not clear, the avalanche maximum run-out zones are very difficult to determine and map. In these cases, application of statistical models based on topographic parameters can be used to improve the cartography. The models use a good-quality set of known extreme avalanches; from this set, topographic parameters that describe each avalanche path and the extreme run-out distance can be measured objectively (in the field or from maps) and statistical models can be developed.

The first work dealing with statistical run-out distance prediction, based on regression analysis, was that of Bovis and Mears (1976). Later, this method was mainly developed by the Norwegian Geotechnical Institute (NGI: Lied and Bakkehøi, 1980; Bakkehøi and others, 1983; Lied and Toppe, 1989). McClung and Lied (1987) proposed the "run-out ratio" method, based on extreme-value statistics. Adjel (1996) compiled a comprehensive review of earlier work on both methods of statistical prediction and applied them to the French Alps.

McClung and others (1989) compared data from four mountain ranges and concluded there was a significant difference in predicted run-out distances as terrain in mountain ranges varies, so it would not be advisable to predict run-out in one range based on data from another.

This paper presents the results from the first statistical models calculated for the Catalan Pyrenees. In this initial attempt only the regression approach has been followed.

\section{AVALANCHE DATA AND GIS INTEGRATION}

The avalanche data used in this work were obtained from 1:50000 scale avalanche-location maps (Furdada, 1996; personal communication from Sabot and Furdada, 1996, http:/(www.ub.es/allaus/tesi.htm). The cartography was done from photo-interpretation, field recognition and, when possible, local information. This mapping is complemented by the Avalanche Cadastre, in which a description of each avalanche path, and all the historical information available, is registered.

The cartography was integrated in the Arc/Info (version 6) geographical-information system (GIS) (Furdada and others, 1995) installed on a SUN SPARC server (UNIX). Digital topographic maps, with an original scale of 1:50 000 provided by the SGE (Army Geographic Survey), were used as the basis for the avalanche maps. Avalanche envelopes were digitized, topology created and attributes defining the origin of the information were codified (such as photo-interpretation, field recognition and inquiries resulted in data with different degrees of reliability). 
From these maps, a set of "well-known" avalanches was selected. Avalanches that run up the opposite mountainside, with obstacles in the run-out zone and with vertical drops less than $300 \mathrm{~m}$ were excluded. The historical data (not very abundant), the morphologic indices and the vegetation affected by extreme avalanches (that recovers in about 30 years) imply that the return periods of the considered "well-known avalanches" range from 30-300 years. From the 307 avalanches selected initially, a set of 216 avalanches was retained (most of the rejected avalanches stopped on slopes with an angle $>10^{\circ}$, see next section).

In statistical treatments, such as the present work, avalanches can be represented by their longitudinal profiles (Lied and Toppe, 1989). Thus, profiles of the set of wellknown avalanches were also digitized, beginning from the top of the starting zone to the end of the run-out zone and following the most likely main flux-line of each avalanche.

One of the capabilities of the Arc/Info TIN module is the generation of Tins (triangulated irregular networks). Tins are digital elevation models (DEMs) constituted by triangles derived from irregularly spaced sample points, e.g. points constituting digital contour lines. An error that produces flat triangles (slope of $0^{\circ}$ ) sometimes appears in small areas with acute inflexions of the contour lines. This usually corresponds to crests and talwegs, thus to avalanche profiles. Several tests were performed to build the best Tin from the 1:50000 scale digital maps; the best solution, that has maintained resolution and avoided generation of these flat triangles as much as possible, was retained.

By using the TIN module, the topographic profiles of the avalanches were obtained (from digitized profiles over the Tin DEM).

\section{ACQUISITION OF TOPOGRAPHIC PARAMETERS}

The topographic parameters used in this work (Fig. 1) were those used in previously by the NGI but slightly modified:

The topographic profiles generated by Arc/Info were exported to a spread-sheet to calculate the topographic parameters. As there is very often more than one $10^{\circ}$ point along a topographic profile (due to small irregularities, or to the existence of a cirque or topographic thresholds in the higher parts of some paths), the idea of Lied and Toppe (1989) was applied: a $10^{\circ}$ point, corresponding to the $\beta$ angle, is accepted only if it is within the section of the profile shown in Figure 2; this section is limited by the points where the angle between the tangent of the best-fitting parabola and the horizontal plane is between $5^{\circ}$ and $15^{\circ}$. The same method was applied to accept the $28^{\circ}$ point corresponding to $\theta$.

But for most profiles, this " $\beta$ field" could not be used; though the correlation coefficient of the best-fitted parabola to the profile was always higher than 0.95 , it was not representative of the lower part of the profile (Fig. 3) except for profiles with a very clear parabolic shape; its vertices did not approach the extreme run-out point and the " $\beta$ field" could not be defined on the profile. As a consequence, in many cases with more than one $10^{\circ}$ point along the profile, the $10^{\circ}$ point corresponding to the $\beta$ angle was chosen by expert criteria. This implies that a certain degree of subjectivity was introduced into the process.

In most cases of avalanches without a clear "parabolic" morphology, the parameter $y^{\prime \prime}$ was not representative of the whole-path curvature, especially in the run-out zone (Fig. oi.org/10.3189/1998AoG26-1-285-288 Published online by Cambridge University Press 286

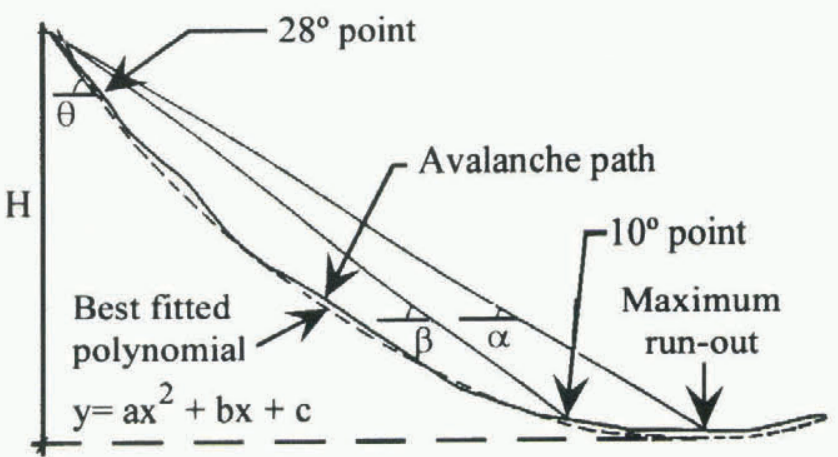

Fig. 1. Topographic parameters for the calculation of maximum run-out distances used in this work. $\alpha\left(^{\circ}\right)$ is the inclination of the straight line between the observed outer end of avalanche debris and the starting point or gradient of the avalanche path and represents the maximum run-out distance; $\beta\left(^{\circ}\right)$ is the inclination of the straight line between the point on the terrain profile where the slope angle equals $10^{\circ}$, and the starting point or gradient of the track; $\theta\left({ }^{\circ}\right)$ is the angle of the straight line between the point on the terrain profile where the slope equals $28^{\circ}$, and the starting point or gradient of the starting zone; $y^{\prime \prime}\left(\mathrm{m}^{-1}\right)$ is the second derivative of the second polynomial equation that best fits the avalanche path, and represents the path curvature; $H(m)$ is the vertical drop of the avalanche path. In their work, McClung and Lied (1987) state that this vertical drop can, in most cases, be taken as the vertical drop between the starting point and the parabola vertex that best fits the avalanche path, so $H$ can be used as a predictor variable.

3). Moreover, the parameter $H$ was not clearly related to the vertical drop from the starting point to the parabola vertex, so $H$ would be unknown for the avalanches to be estimated (Fig. 3). We, therefore, considered we could use these parameters as predictor variables only for full "parabolic" profiles.

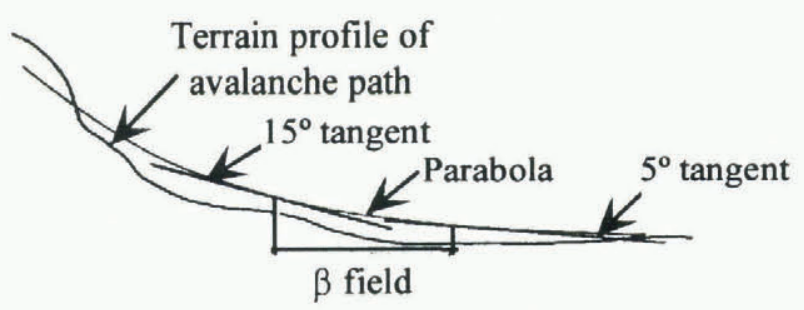

Fig. 2. Definition of the " $\beta$ field" using the best-fitting parabola to locate the $10^{\circ}$ point (Lied and Toppe, 1989).

As the run-out zone morphology has a great influence on the deceleration and stopping of avalanches, we classified the profiles according to this. Three classes were distinguished: 64 full "parabolic" profiles (the entire profile had quite a good parabolic morphology), 62 profiles with a "parabolic run-out zone" and 56 profiles with a brusque slope rupture in the run-out zone. There were also 34 irregular profiles which were difficult to classify. The parameters that could be used as predictor variables for each class were retained.

Table 1 shows the descriptive statistics of the data used; it only shows the parameters that enter the regression equations presented in this paper.

Comparison of the $\alpha$ and $\beta$ parameters shows that profiles with brusque slope rupture in the run-out zone are 
a

m.a.s.l.

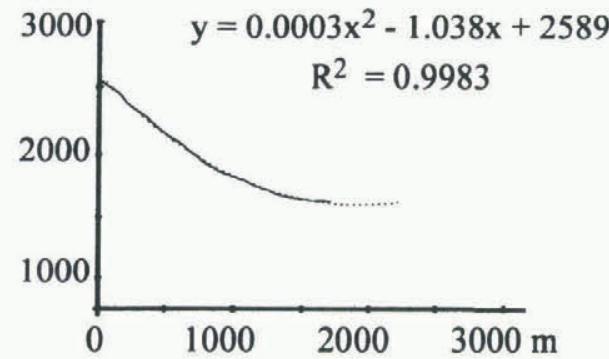

m.a.s.l.

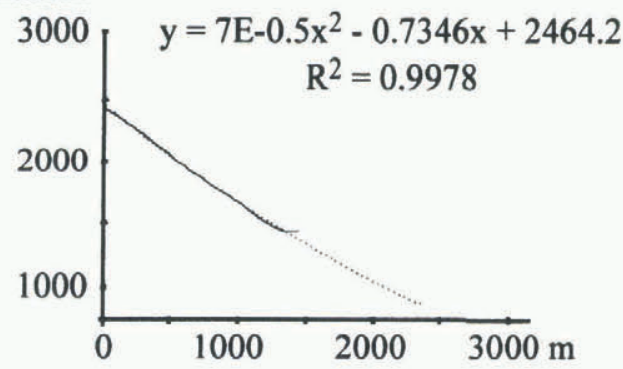

b

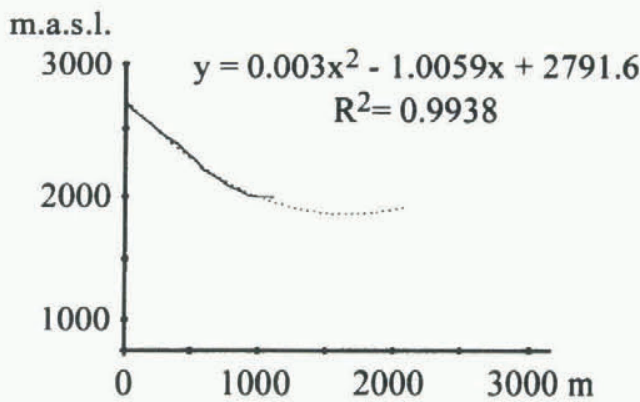

d

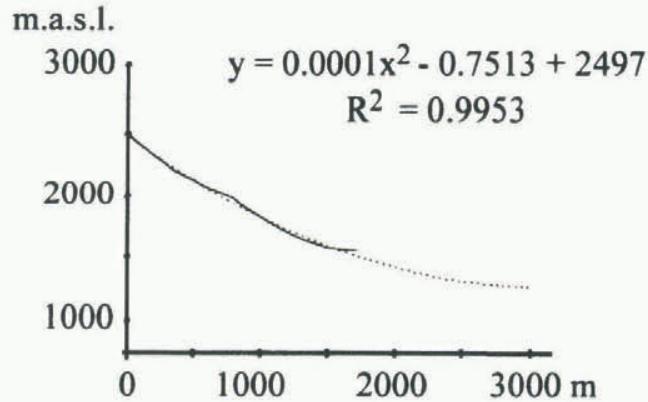

Fig. 3. Longitudinal topographic profiles (continuous lines) with their best-fitting parabolae (dashed lines): (a) the parabola is a good representation of the profile; ( $b$ ) though the profile has a "parabolic" run-out zone, the best-fitting parabola does not fit well enough in the lower zone; $(c)$ in the profiles with a brusque slope rupture in the run-out zone, the parabola does not fit in the lower zone; (d) the profile is irregular. For b, $c$ and d the best-fitting parabolae are not representative of the whole-path curvature and of the vertical drop of the avalanche.

Table 1. Descriptive statistics for run-out parameters.

(Only the parameters of the equations presented are indicated)

\begin{tabular}{lccccc}
\hline No. of profiles /class & Parameter & $\begin{array}{c}\text { Mean } \\
\text { value }\end{array}$ & Std. dev. & Median & Range of values \\
& & & & \\
\hline 64: "Parabolic" & $\alpha\left({ }^{\circ}\right)$ & 24.67 & 3.90 & 24.41 & $17.57-37.12$ \\
& $\beta\left({ }^{\circ}\right)$ & 27.34 & 3.90 & 27.39 & $20.07-38.27$ \\
& $\theta\left({ }^{\circ}\right)$ & 34.01 & 3.38 & 33.67 & $25.70-43.62$ \\
& $\mathrm{H}(\mathrm{m})$ & 753.32 & 262.47 & 750.30 & $300.64-1431.80$ \\
64: "Parabolic" run-out & $y^{\prime \prime}\left(* \mathrm{~m}^{-1}\right)$ & 0.528 & 0.348 & 0.4 & $0.08-1.6$ \\
& $\alpha\left({ }^{\circ}\right)$ & 28.10 & 4.10 & 27.89 & $20.17-39.78$ \\
56: Brusque slope rupture & $\beta\left(\left(^{\circ}\right)\right.$ & 30.00 & 4.24 & 29.62 & $21.73-41.70$ \\
& $\alpha\left({ }^{\circ}\right)$ & 29.48 & 5.45 & 29.49 & $18.23-41.56$ \\
216: Complete profiles set & $\beta\left(\left(^{\circ}\right)\right.$ & 31.62 & 5.28 & 32.11 & $20.65-43.09$ \\
& $\alpha\left({ }^{\circ}\right)$ & 27.27 & 4.91 & 27.14 & $17.57-41.56$ \\
& $\beta\left({ }^{\circ}\right)$ & 29.52 & 4.77 & 29.14 & $19.02-43.09$ \\
\hline
\end{tabular}

steeper and have shorter run-out distances than profiles with "parabolic" run-out, and the same happens when the full "parabolic" profiles are compared with profiles with "parabolic" run-out.

\section{RESULTS AND APPLICABILITY OF THE MODELS}

Regression models for each class of profile were obtained from simple- and multiple-regression (at least by using $\beta$ and $\theta$, and therefore considering that the steepness of the starting zone could influence the maximum run-out distance). The best regressions obtained for each class and for the whole set of profiles are the following (where $R^{2}$ is the ordinary correlation coefficient and $\sigma$ is the standard deviation of the residuals):

For 64 full "parabolic" profiles:

$$
\hat{\alpha}=1.05+0.86 \beta \quad R^{2}=0.75 \quad \sigma=1.98^{\circ} .
$$

For these "parabolic" profiles, the best result of multipleregression analysis does not produce a significant improvement over the previous model presented:

$$
\begin{aligned}
& \hat{\alpha}=8.45+0.48 \beta+ 10^{-3} 0.2 H y^{\prime \prime} \theta \\
& R^{2}=0.78 \quad \sigma=1.85^{\circ},
\end{aligned}
$$

so it is advisable to use the first one, which is simpler and provides similar results. 
For 62 profiles with "parabolic run-out zone":

$$
\hat{\alpha}=-0.03+0.94 \beta \quad R^{2}=0.94 \quad \sigma=1.01^{\circ} .
$$

For 56 profiles with a brusque slope rupture in the runout zone:

$$
\hat{\alpha}=-1.02+0.97 \beta \quad R^{2}=0.87 \quad \sigma=1.94^{\circ} .
$$

For all the 216 profiles studied:

$$
\hat{\alpha}=-1.20+0.97 \beta \quad R^{2}=0.87 \quad \sigma=1.74^{\circ} .
$$

In all cases, and as it happened in previous works (e.g. McClung and Lied, 1987), $\theta$ did not improve the prediction of $\alpha$ through a bivariable (or multi-variable, in the case of the "parabolic" profiles) relationship including $\beta$. In all cases, $\beta$ also turned out to be the best predicting parameter for $\alpha$.

The main purpose of these models is to help determine run-out distances. An important question is whether they can be used to improve mapping and, if so, how accurate they are. As a first approach, and assuming horizontal runout zones (Lied and Bakkehøi, 1980), $\Delta L$ can be expressed as the following:

$$
\Delta L=L-L^{\prime}=(1 / \tan \alpha-1 / \tan (\alpha+\Delta \alpha)) H
$$

where $L$ is the total horizontal displacement.

If, in another approximation, one considers that $\Delta \alpha=\sigma$ (where $\sigma$ is the standard deviation of the residuals), $\Delta L$ can be calculated for each model and for different $\beta$ and $H$ values. After calculating some of these $\Delta L$ and translating them to a scale of 1:50000 the results obtained were as follows:

For medium avalanches (i.e. $H=750 \mathrm{~m}, \beta=28^{\circ}$ ) and all models, the maximum run-out location had a possible error of about 5-6 mm (250-300 m) on a 1:50000 scale map. When applying the most general equation (calculated from the 216 avalanches), the maximum run-out distance of the "parabolic" profiles turned out to be slightly underestimated, whereas for the profiles with a brusque slope rupture, this distance was slightly overestimated. This under- or overestimation corresponds anyway to less than $1 \mathrm{~mm}$ on a 1:50 000 map. Therefore, the general equation can be used to estimate all kinds of avalanches considered in this work.

For large avalanches (i.e. $H=1400 \mathrm{~m}, \beta=28^{\circ}$ ), the maximum run-out-location possible error was approximately $10 \mathrm{~mm}(500 \mathrm{~m})$ on a 1:50000 scale map. Looking at the relatively small dimensions of the Pyrenean valleys and their land-use, the models do not contribute to mapping these large avalanches.

\section{CONSIDERATIONS AND CONCLUSIONS}

One of the limitations of the method is that it presupposes the existence of only one $10^{\circ}$ slope point along the profile (Adjel, 1996). Often there are more than one such point; this forces us to reject many profiles, if an objective, automatic method is used to identify the $10^{\circ}$ point and calculate the $\beta$ parameter. Otherwise, a degree of subjectivity is introduced when choosing the "correct" $10^{\circ}$ point.

In this work, pre-selection of the treated avalanche paths implies that not all unknown avalanche run-out zones can be estimated using these equations.
As observed in previous work (reviewed by Adjel, 1996), $\beta$ is the best predictor variable to estimate $\alpha$. In our work, multi-variable regressions do not improve the results or do not have statistical significance.

The consequences of the application of these models on mapping will depend, of course, on the dimensions of the avalanche considered. In the Pyrenees, the results estimated for small- to medium-avalanches $(300 \mathrm{~m}<$ vertical drop $<$ $750 \mathrm{~m}$ ) may be acceptable in some cases but useless for larger avalanches.

The scale of the maps, at the limit of the desired resolution, and the random error introduced by the return-period data, limit the topographic data used and the results of the statistical treatment; more detailed topographic data and more historical data might improve the regression models presented, thus providing better results.

In this vein, the availability of new topographic data at a scale of 1:10000 (produced by the ICC) and Arc/Info (version 7) can improve the topographic inputs. Version 7 of Arc/Info allows the inclusion of "break-lines" to control the correct modelling of crests and talwegs in the DEM generation process, thus improving the resulting DEM and maintaining resolution at the same time.

Furthermore, the integration of avalanche data from the 1996 winter (with large avalanches, probably corresponding to a return period of 100 years or more), which were not considered in this work, will probably help to improve the models.

\section{ACKNOWLEDGEMENTS}

This study was supported by Project Estudi del Risc d'Allaus al Pirineu de Catalunya from the Departamenta P.T. O. P., Generalitat de Catalunya; the CICYT Project (No. AMB930837) the Ajut CIRIT (1992) (AIREII/1-4), and the Human Capital and Mobility Program (No. CHRX-CT93-0307 DG 12 COMA). We would like to thank F. Sabot, G. Adjel and J. Corbera for their comments and encouragement.

\section{REFERENGES}

Adjel, G. 1996. Méthodes statistiques pour la détermination de la distance d'arrêt des avalanches. (Thèse de doctorat, Université Joseph FourierGrenoble I.)

Bakkehøi, S., U. Domaas and K. Lied. 1983. Calculation of snow avalanche runout distance. Ann. Glaciol., 4, 24-29.

Bovis, M. J. and A. I. Mears. 1976. Statistical prediction of snow avalanche runout from terrain variables in Colorado. Arct. Alp. Res., 8(1), 115-120.

Furdada, G. 1996. Estudi de les allaus al Pirineu Occidental de Catalunya: predicció espacial $i$ aplicacions de la cartografía. Logroño, Geoforma ediciones.

Furdada, G., G. Martí, P. Oller, C. García, M. Mases and J. M. Vilaplana. 1995. Avalanche mapping and related G.I.S. applications in the Catalan Pyrenees. Surv. Geophys., 16 (5 - 6), 681-693.

Lied, K. and S. Bakkehøi. 1980. Empirical calculations of snow-avalanche run-out distance based on topographic parameters. 7. Glaciol., 26(94), $165-177$.

Lied, K. and R. Toppe. 1989. Calculation of maximum snow-avalanche runout distance by use of digital terrain models. Ann. Glaciol., 13, 164-169.

McClung, D. M. and K. Lied. 1987. Statistical and geometrical definition of snow avalanche runout. Cold Reg. Sci. Technol., 13 (2), 107-119.

McClung, D. M., A. I. Mears and P. A. Schaerer. 1989. Extreme avalanche run-out: data from four mountain ranges. Ann. Glaciol., 13, 180-184. 